\title{
IN VIVO BIOCOMPATIBILITY OF $\beta$ TRI-CALICUM PHOSPHATE VERSUS WHITE PORTLAND CEMENT IN MANDIBULAR BONE SURGICAL DEFECT IN DOGS
}

\author{
Altaib Abdel Razik Mohammed *, Reda Gaber Saleh **, Doaa A. Taiema **, \\ Abdel-Nasser A.A. Abdel-Hady ***, Asmaa, A. Metwally ****
}

\begin{abstract}
Back ground: Synthetic bone substitutes have been advanced, and researches are developed to more effective biomaterials with promising ability to reconstruct lost bone structure. Tricalcium phosphate biomaterials and white Portland cement are among them. The aim of the current study is to assess the effect of $\beta$-tricalcium phosphate versus white Portland cement in surgically mandibular bone defect dogs.
\end{abstract}

Material and methods: Six adult dogs were used. The anaesthesia was conducted by iv injection of thiopental sodium $20 \mathrm{mg} / \mathrm{kg}$.b.wt. and maintained using (atropine $0.04 \mathrm{mg} / \mathrm{kg}$ b.wt., xylazine $1 \mathrm{mg} / \mathrm{kg}$.b.wt. and diazepam $1 \mathrm{mg} / \mathrm{kg}$.b.wt.in saline iv drop by drop infusion ), three critical size defects were designed at the buccal side of the mandible. The defects were $5 \mathrm{~cm}$ apart from each other. One defects filled with sterile white Portland cement, the middle defect filled with $\beta$-tricalcium phosphate and the later one was left empty. The dogs were euthanized at the end of 1 and 8 week postoperatively respectively. The specimens were prepared for light microscope using $\mathrm{H} \& \mathrm{E}$ and Masson Tri-chrome staining.

Results: The experimental sides of all periods revealed increasing the amount of new bone trabeculae extended from original bone towards the center of the defect with both white Portland cement $\& \beta$-tricalcium phosphate. While, the control sides displayed few new bone trabeculae at central area and the lateral wall of the bony defects. The amount of new bone trabeculae confirmed the histological results.

Conclusion: White Portland cement is a biocompatible osteoconductive economically affordable graft material and it id more efficient than $\beta$-tricalcium phosphate.

\footnotetext{
* Departments of Oral and Maxillofacial Surgery, Faculty of Dentistry, South Valley University.

** Oral Biology and Histology, Faculty of Dentistry, Tanta University.

*** Surgery, Anaesthesiology and Radiology and the Head of the Department, Faculty of veterinary medicine, South Valley University. Qena.

**** Surgery, Anaesthesiology and Radiology, Faculty of veterinary medicine, Aswan University,
} 


\section{INTRODUCTION}

Abbrivation: $\beta$-tricalcium phosphate ( $\beta$-TCP), white Portland cement (WPC), Portland cement (PC), Mineral trioxide aggregate (MTA), Massontrichrome staining (MT).

Alveolar bone is a specialized part of the mandible and maxilla that forms the primary support structure for teeth. Although it compared to other bone tissues in the body, alveolar bone is exposed to constant and rapid remodeling associated with tooth eruption and consequently the functional demands of mastication. The anatomy of alveolar bone, which is relatively complex, has been described in detail $^{[1]}$.

Alveolar bone is composed of bundle bone, which is fashioned in layers in a parallel alignment to the coronal-apical direction of the tooth. Sharpey's fibers boost obliquely from the thin lamella of bone that outlines the socket wall and are continued with fibers of the periodontal ligament. A thicker outer layer of bone formed of cortical plates covers the jaw bone and modes the lingual and labial surfaces of the alveolar process and is built up mainly of spongy cancellous bone. In the cancellous bone numerous marrow spaces, with smaller endosteal spaces exist in the cortical bone. Some of the small endosteal spaces broaden into, and are attached with, the periodontal ligament ${ }^{[2]}$.

Effective repair of bone deficiencies in the cranio-facial skeleton, in case of trauma, tumor resection, or congenital disorders, continues to be a major concern to reconstructive surgeons. Bone grafting is a surgical replacement the missed bone with substantial from the patient's own body ${ }^{[3]}$.

The benefit of autologous bone grafts is considered to be the excellent standard for repair and reconstruction of bone. It has major impediment, inadequate amount, donor site morbidity, and unfortunate form ${ }^{[4]}$.

Researches in alternative bone grafts such as allografts (tissue from other person of the clone species) and xenografts (animal tissues). They are attractive sources, there are several problems encountered in using them including hazard of disease transmission, immunogenic response, and variable quality associated with allografts, impress the necessity for alternative approaches ${ }^{[5]}$.

Significant efforts are being made to develop ideal synthetic bone graft substitutes. The ultimate circumstances of a bone graft are determined by three parallel phenomena, namely osteoconduction, osteoinduction, and osteogenesis ${ }^{[6]}$. In osteoconduction, the graft material furnishes a scaffold for osteoblasts to grow on its surface. Osteoinduction stimulates differentiation of primitive, undifferentiated, and pluripotent cells to osteoblasts. Osteogenesis develops when graft material has viable osteoblasts adept in repair of the bony defect ${ }^{[7] .}$

The remodeling process for osteoconductive materials is well described. Different osteoconductive materials lead to discrepancy rates of remodeling with secondary inflammation and fibrosis at the remodeling sites ${ }^{[8]}$. Osteoconductive materials when placed in well vascularized location with influence of medullary elements have copious access to growth factors and proteins important to bone production and remodeling as well as osteoprogenitor cells ${ }^{[9]}$. There have been many studies explored the aptitude of osteogenetic biomaterials. However, the difference in reparative response of bone affected by osteoconductive properties of particular synthetic and natural materials has not been thoroughly described.

Calcium phosphate biomaterials such as hydroxyapatite and tricalcium phosphate are frequently applied biomaterials because they are significantly biocompatible, osteoconductive and gradually resorbed and replaced with bone. Two major distinct phases of anhydrous TCP crystals exist: $\alpha$-TCP and $\beta$-TCP phases ${ }^{[10] \text {. }}$ 
Kihara et al ${ }^{[11]}$ investigated biodegradation process of TCP particles and new bone formation in a rabbit cranial defect model and established that TCP particles are osteoconductive and spacemaintaining.

$\beta$-TCP is osteoconductive material acting as space maintainer for bone formation. This biomaterials would be considered auspicious and cost-adequate in maxillofacial bone regeneration, in periapical, periodontal and peri-implant bone defects as well as reduced alveolar bone volume for prosthetic rehabilitations ${ }^{[12]}$.

MTA, a Portland cement-based material, has various endodontic applications. MTA's propriety in the treatment of non-vital immature teeth has been investigated [13]. The principal ingredients and the total of arsenic in PC as well as its bio-compatibility and physicochemical behavior, are similar to those of MTA. The setting time of PC can be shorted by eliminating gypsum from manufacturing process without affecting other properties ${ }^{[14]}$.

Abdullah et al ${ }^{[15]} \&$ Bidar et al, ${ }^{[16]}$ prepared PC with they investigated the biocompatibility of PC in vitro by noticing the cytomorphology of $\mathrm{SaOS} 2$ (human osteosarcoma cells) in the presence of PC and its effect on the expression of markers of bone remodeling. They ensued that APC is non-toxic and may have prospective to enhance bone healing.

In the present study, we analyzed the histological and cellular events in bone regeneration in response to implantation of TCP, PC into experimentally designed intra-bony defects in dog mandibles. Moreover, we aimed to compare these materials with each other in terms of osteogenesis.

\section{MATERIALS AND METHODS}

\section{Animals}

Six 2-year-old mongrel dogs with intact dentition and good periodontium were selected (about $20 \mathrm{~kg}$ in weight). The dogs were evaluated thoroughly in teaching veterinary clinic observed for 14 days preoperatively for free of any diseases. The dogs were housed in separate cages in the animal house (Faculty of Veterinary Medicine, Department of surgery, anaesthesiology and radiology, South Valley University) and maintained according to guide for care and practice of laboratory animals. The protocol of the study was performed and carried out according to the guidelines of ethical committee of Faculty of Medicine South Valley University.

The animals were starved for 12 hours before anaesthesia. The anaesthesia was induced by iv injection of thiopental sodium $20 \mathrm{mg} / \mathrm{kg}$.b.wt. and maintained using (atropine $0.04 \mathrm{mg} / \mathrm{kg}$ b.wt, xylazine $1 \mathrm{mg} / \mathrm{kg}$.b.wt. and diazepam $1 \mathrm{mg} / \mathrm{kg}$.b.wt. in saline iv drop by drop infusion) through cannula.

\section{Materials}

1. Sterile powder of WPC (Oasis White Portaland Cement 11/B-L42.Sn Helwan Cement Ital Cement Group). WPC powder was sterilized by autoclaving according to Ravi et a $\mathrm{l}^{[17]}$ temperatur $134^{\circ}$ for 15 minutes in air tight closed bottle.

2. Iceber $\beta$-TCP (GMI iler implant group, Espania) is a porous $\beta$-TCP synthetic graft in a granular form with a particle size of size $300-500$ microns.

\section{Experimental design}

The operative site was prepared using povidone iodine and infiltration anesthesia was fulfilled using $2 \%$ mepivacaine with adrenaline for hemostasis, using scalpel blade No 15 vestibular incision was designed $2 \mathrm{~cm}$ in length and the mucoperiostium was reflected and three critical size defects were designed at the buccal surface of the mandible $4 \mathrm{~mm}$ away from the lower border.

The defect is $6 \mathrm{~mm}$ in diameter and $6 \mathrm{~m}$ in depth. It is created by trephination bur under copious saline irrigation. The defects were $5 \mathrm{~cm}$ apart from each other $^{[18]}$ (Fig.1A). 
Each dog had 3defects on the buccal surface of the mandible that are designed as follow:

\section{Group I}

Defects at left side were left empty.

\section{Group II}

Defects at the middle were filled with $\beta$-TCP

\section{Group III}

Defects at right side were filled with sterile WPC

The wounds were closed using 3-0 vicryl. Penicillin and streptomycin veterinary preparation was injected twice for 3 days for prophylaxis against infection. Also voltarin was used as analgesic as it is injected twice daily for 3 days.

The dogs were kept on soft diet in assemble of bread and milk for a week and dry foods were introduced freely to the dogs, the dogs were cared, and the wound was examined for any swelling, infection and dehiscence.

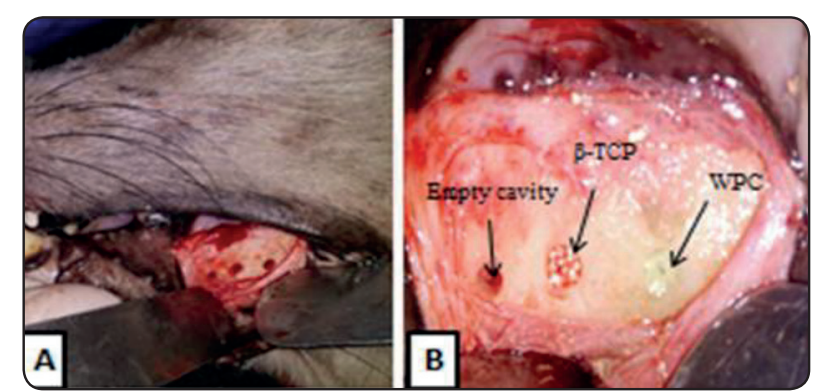

Fig. (1): A. Three equal defects at the buccal surface of the mandible near lower border B. The defects filled with test materials

Three dogs were sacrificed after $1^{\text {st }}$ and $8^{\text {th }}$ week postoperatively respectively. On scarification of the dogs, ketamine was injected and the mandibular bone segments were osteotomized for histologic examination.

\section{Light microscopic study}

Biopsies were fixed in $10 \%$ buffered formalin for 24 h. Specimens were decalcified in $10 \%$ EDTA.
The Specimens washed in tap water over night and then dried out in ascending grades of alcohol, cleared in xylene and then implanted in low melting point $\left(56^{\circ} \mathrm{C}\right)$ paraffin. Serial sections of 5 um thickness were cut down with rotary microtome (lyca) and then processed for $\mathrm{H} \& \mathrm{E}$ and MT staining, then were observed under the light microscope ${ }^{[19]}$.

\section{Statistical histomorphometric analysis of newly formed bone filling the defect:}

After processing and staining of MT staining, images were analyzed for quantitative measurement of newly formed using the ImageJ analysis system. All statistical analyses were performed using the (ANOVA) followed by t-test. All values were expressed as means and standard deviations. All statistical analyses were done on an IBM PC using the statistical software "SPSS 20". Results were expressed in the form probability value ( $p$-value) that was differentiated into: non-significant when $\mathrm{p}$-value $>0.05$, significant when $\mathrm{p}$-value $\leq 0.05$, highly significant when $p$-value $\leq 0.01$, very highly significant when $\mathrm{p}$-value $\leq 0.001$.

\section{THE RESULTS}

The postoperative periods passed smoothly, the post-operative oedema was slight and gradually disappeared, and the healing of the wound was eventful ( Fig.2).

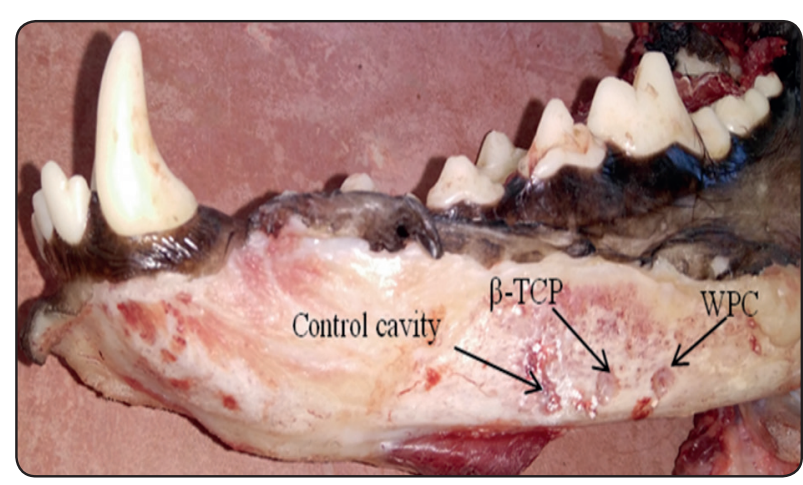

Fig. (2): Healing of the test materials 


\section{Light microscopic results}

\section{H \&E Staining:}

\subsection{Control group:}

At the end of $1^{\text {st }}$ week, a fibrous tissue occurred around at the edges of the defect, granulation tissue was appeared filling the bony defect. A combination of spindle cells with elongated nuclei and small rounded cells with large nuclei were detected in the connective tissue. There was evident osteoclastic activity (Fig. 3 A,B).

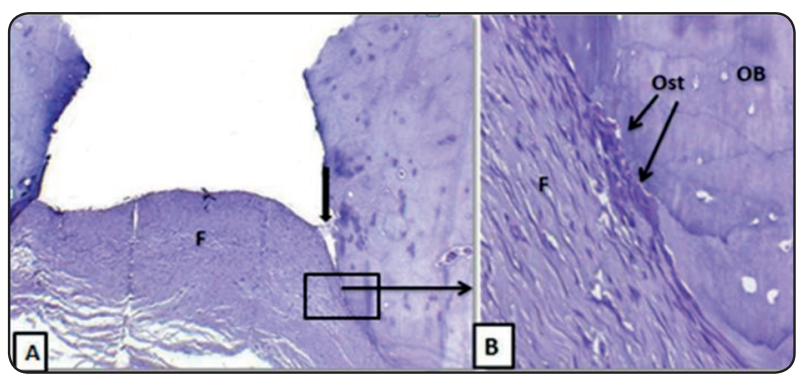

Fig. (3): Photomicrograph of a group I (control gp.) taken at the end of 1st week F: Fibrotic tissue growth, moderate Inflammation (arrow). A. Defect occupied with fibrous tissue $(\mathrm{F})$ along with a clear edge of native bone. B. High magnification of figure A, F: Fibrotic tissue growth, and Ost: Osteoclastic activity, OB: Old bone. A combination of spindle cells, elongated nuclei and small rounded cells with large nuclei were detected in the connective tissue. Osteoclastic activity was evident. $(\mathrm{H} \& \mathrm{E} \mathrm{A} \times 10, \mathrm{~B} \times 40)$.

At the end of $8^{\text {th }}$ week, few new bone trabeculae were observed at central area and the lateral wall of the bony defect, they were lined by active osteoblast with areas of osteoclastic activity. Large areas of CT were noticed (Fig. 6 A,B).

\section{2. $\beta$-TCP group:}

At the end of $1^{\text {st }}$ week, moderate inflamed high cellular CT with collagen fibers and woven bone that is molded at the boundaries of the defect areas in contact with old bone, numerous blood vessels colonizing the granulation tissue, reversal line separating old bone from new bone (Fig. 4 A,B).

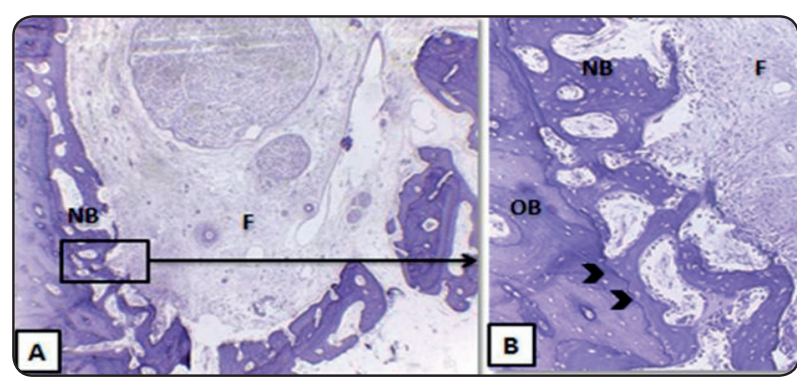

Fig. (4): Photomicrographs of a group II ( $\beta$-TCP gp.) taken at the end of 1st week F: Fibrotic tissue growth, New bone (NB). A. Woven bone observed at the boundaries of the defects. The defect was full with fibrous tissue. B. High magnification of figure A. Woven bone assembled at the boundaries of the defect areas in contact with old bone, numerous blood vessels colonizing the granulation tissue, reversal line (arrow head) separating old bone $(\mathrm{OB})$ from new bone $(\mathrm{NB})(\mathrm{H} \& \mathrm{E} \mathrm{A} \times 10, \mathrm{~B} \times 40)$.

At the end of $8^{\text {th }}$ week, new woven bone were observed at the boundaries of the defects in contact with old bone, filling large areas of the bony defect, with variable sizes of bone marrow cavities. New bone trabecula have mature osteocytes in their lacunae (Fig. 7 A,B).

\subsection{WPC group:}

At the end of $1^{\text {st }}$ week, abundant woven bone assembled at the boundaries of the defect areas. New bone trabecula surrounded by $\mathrm{CT}$ and large blood vessels. There were active osteoblasts lining the new bone (Fig. 5 A,B).

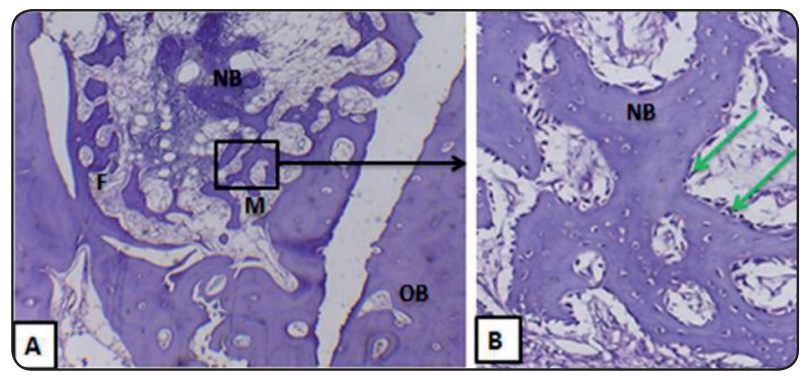

Fig. (5): Photomicrographs of a group III (WPC gp.) taken at the end of 1st week F: Fibrotic tissue growth, New bone (NB), Old bone (OB), Bone marrow (M). A. Abundant woven bone assembled at the boundaries of the defect areas. B. High magnification of figure A. NB trabecula surrounded by $\mathrm{CT}$ and large blood vessels, active osteoblast (green arrow) lining the NB. $(\mathrm{H} \& \mathrm{E}, \mathrm{A} \times 10, \mathrm{~B} \times 40)$. 


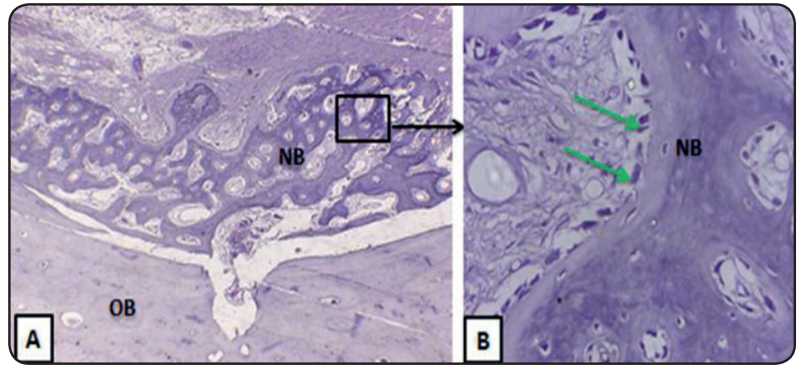

Fig. (6): Photomicrograph of a group I (control gp.) taken at the end of 8thweek A. shows Few bone trabecula (NB) at the center of bone defect. Old bone at extermity of the wound (OB). B. High magnification of figure A, NB surrounded is formed, active osteoblast (green arrows) lining the NB. $(\mathrm{H} \& \mathrm{E}, \mathrm{A} \times 10, \mathrm{~B} \times 40)$.

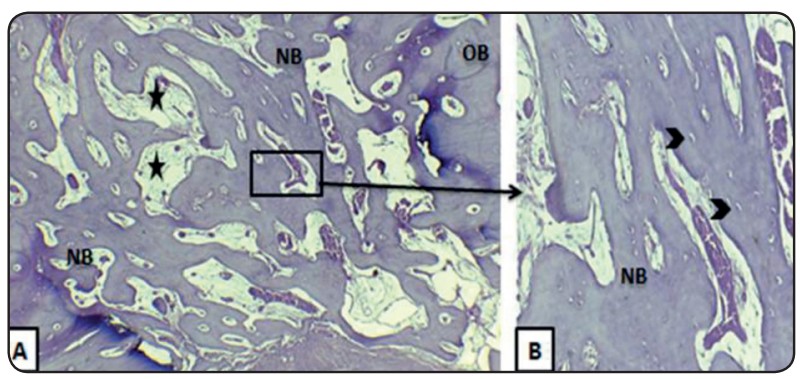

Fig. (7): Photomicrographs of a group II ( $\beta$-TCP gp.) taken at the end of 8 thweek A. shows new woven bone were observed at the boundaries of the defects (NB) in contact with old bone, filling large areas of the bony defect, with variable sizes of bone marrow cavities (stars). B. High magnification of figure A. New bone trabecula (NB) with mature osteocytes in their lacunae (arrow head). (H\&E A $\times 10, \mathrm{~B} \times 40)$.

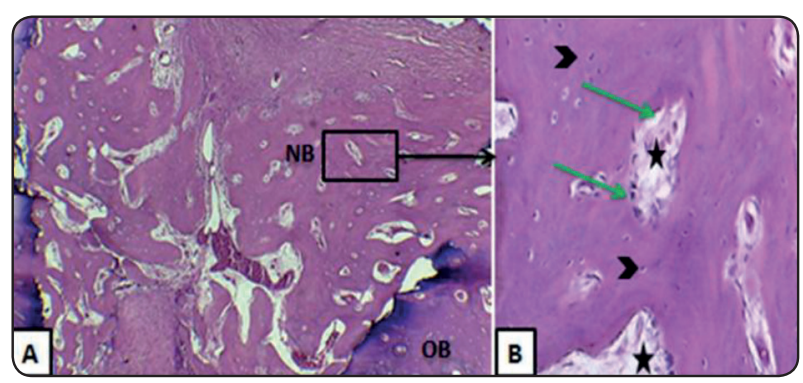

Fig. (8): Photomicrographs of a group III (WPC gp.) taken at the end of 8thweek shows A. well organized large bone trabecula (NB) filling large areas of the bony defect, the most mature one near the old bone $(\mathrm{OB})$. B. Higher magnification of figure A. Mature bone trabecula with large Harversian canal (star), New bone trabecula lined by active osteoblast (green arrows). Mature osteocytes in their lacunae (arrow head). (H\&E orig. mag., $\mathrm{A} \times 10, \mathrm{~B} \times 40)$.
At the end of $8^{\text {th }}$ week, well organized bone trabecula were observed filling large areas of the bony defect, they were lined by active osteoblasts. Large bone marrows were noticed filled with C.T and large blood vessels. New bone trabecula lined by active osteoblast (Fig. $8 \mathrm{~A}, \mathrm{~B}$ ).

\section{Masson's Trichrome staining}

Masson trichrome staining of all the samples presented a red color for cytoplasm, scattered with bits of blue for the bone, which verified wide range of bone tissue in the form of collagen. Collagen was distributed around the bone lacunae.

2.1. At the end of $1^{\text {st }}$ week, (control group) we found lots of blue-staining fibrous tissues, chronic inflammatory cells were detected to infiltrate all defect areas, coarse-fibered CT. There were few bone spicules (Fig 9A). In $\beta$-TCP group, collagen fibers randomly arranged representing an embryonic bone. There was initial bone neoformation (Fig. 9B). In WPC group, the surgical cavity was partially repaired, with incomplete formation of new cortical bone (Fig. 9C).

2.2. At the end of $8^{\text {th }}$ week, (control group) the surgical cavity was repaired with the reorganization of the bone marrow (Fig. 9D). In $\beta$-TCP group, there were bone trabeculae organized (Fig. 9E). In WPC group, the cortical bone was completely repaired, with thick trabeculae are observed and the small connective tissue area (Fig. 9F).

\section{Statistical quantitative evaluation of the newly formed bone:}

At 8th week, experimental side reported the highest mean value of quantitative measurement of newly formed bone with the lowest value in control side at $1^{\text {st }}$ week. Analysis of variance (ANOVA) test revealed a highly significant difference between control \& experimental side ( $p$-value $<0.001)$. In addition to, experimental side in the two periods was showed higher mean value than their corresponding in control side (tab. 1) \& (fig. 10). 


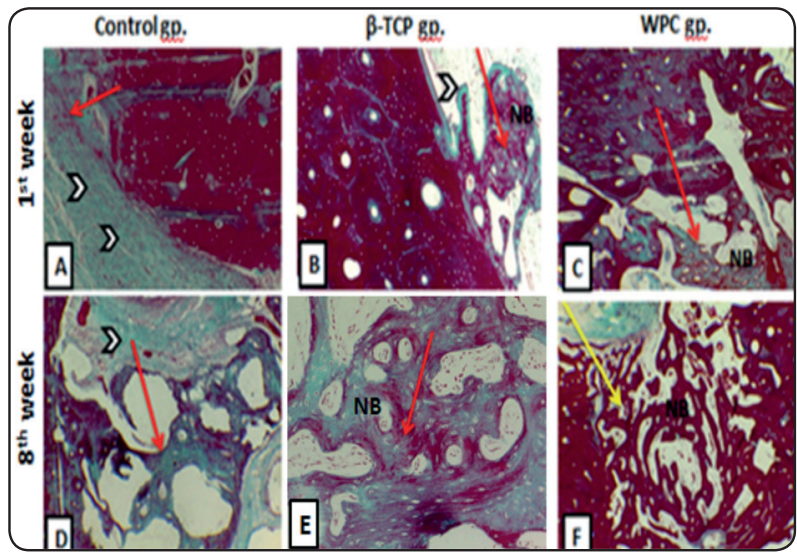

Fig. (9): (A-C), (D-F) representative histological sections of the end of bone defect with Masson's Trichrome staining in (control group, $\beta$-TCP group, WPC group after $1^{\text {st }}$, $8^{\text {th }}$ week Chronic inflammatory cells were detected to infiltrate all defect areas (arrow head). Red arrows indicate the immature bone tissue (NB), and yellow arrows indicate the mature bone tissue. (MT.×20).

TABLE (1): Statistical quantitative analyses of newly formed bone in control and experimental side ( $\beta$ TCP, WPC) at the $1^{\text {st }} \& 8^{\text {th }}$ week.

\begin{tabular}{|c|c|c|c|c|c|c|c|}
\hline & & Range & Mean \pm S. D & F. test & p. value & & \\
\hline \multirow{3}{*}{ 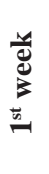 } & Control group & $115-133$ & $123.89 \pm 5.88$ & \multirow{3}{*}{190.427} & \multirow{3}{*}{$0.001 *$} & $\mathrm{P} 1$ & $0.001 *$ \\
\hline & $\beta$-TCP group & $152-176$ & $161.00 \pm 7.40$ & & & $\mathrm{P} 2$ & $0.001 *$ \\
\hline & WPC group & $310-332$ & $321.89 \pm 8.22$ & & & P3 & $0.001 *$ \\
\hline \multirow{3}{*}{ 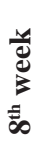 } & Control group & $187-206$ & $196.22 \pm 5.54$ & \multirow{3}{*}{205.864} & \multirow{3}{*}{$0.001 *$} & $\mathrm{P} 1$ & $0.001 *$ \\
\hline & $\beta$-TCP group & $237-266$ & $251.33 \pm 9.17$ & & & $\mathrm{P} 2$ & $0.001^{*}$ \\
\hline & WPC group & $381-415$ & $399.67 \pm 11.53$ & & & P3 & $0.001 *$ \\
\hline
\end{tabular}

\section{* Significant}

\section{P1: Control group \& $\beta$-TCP group}

P2: Control group \& WPC group

P3: $\beta$-TCP group \& WPC group

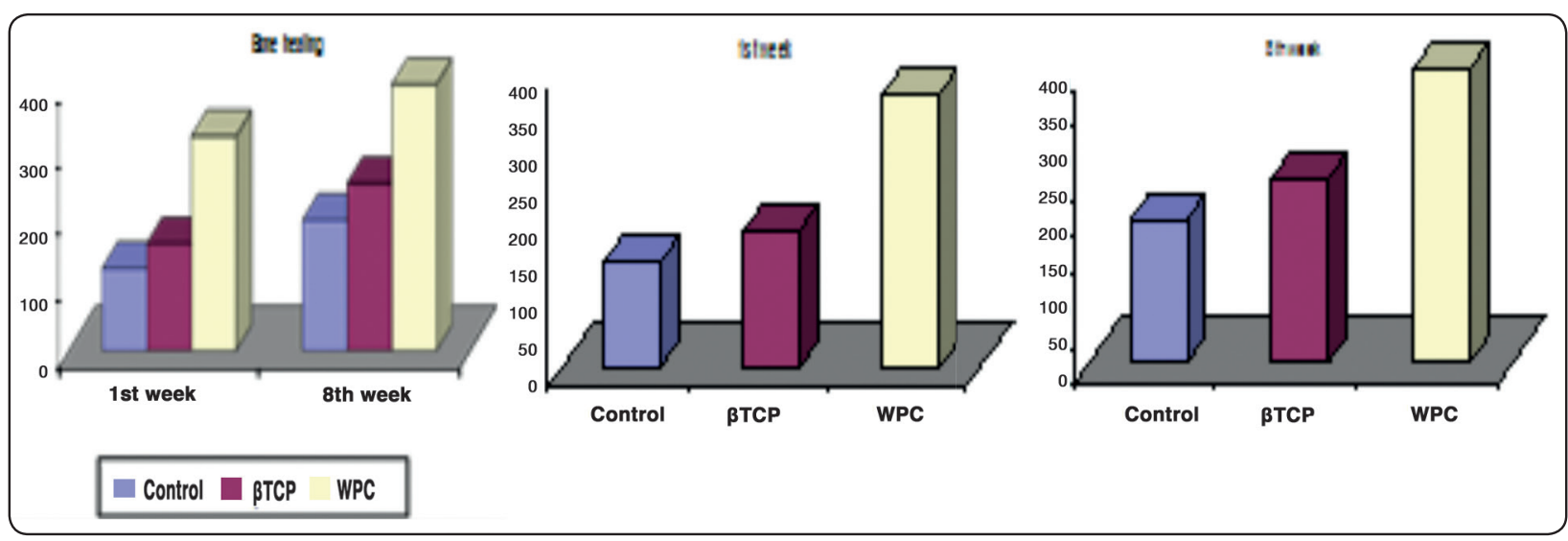

Fig. (10): Column chart representing mean of the quantitative measurement of newly formed bone in control and experimental side $(\beta \mathrm{TCP}, \mathrm{WPC})$ at the $1^{\text {st }}, \& 8^{\text {th }}$ week. 


\section{DISCUSSION}

The present study evaluated the biocompatibility and the bone healing effectiveness following the WPC graft material versus $\beta$ TCP in experimentally created intra bony defects in dog's mandible. In this study the animals were euthanized for evaluation at 1 and 8 weeks after surgery, this research model was selected to be safe for the preservation and quality of animal's life up to the end of the evaluation period. This type of model was used by different experimental research ${ }^{[20]}$. Lower border of the mandible was selected due to ease accessibility and the reasonable size ${ }^{[21]}$.

With the purpose of improving the osteogenic potential of $\beta$-TCP porous ceramics, we evaluated bone enhancement of porous scaffold in bone defect models. Absorptive scaffolds have been studied for decades, the uniform pore architecture of scaffolds looks a significant challenge in inducing the growth of new tissue in the way of natural bone acts ${ }^{[22,23]}$. The architectonic pattern of natural bone can be described as having a stiff, dense external layer of cortical bone, transitioning to a delicate and spongy cancellous bone internally.

There have been establishing a fabrication method to create a kind of scaffold that is both graded and highly interconnected. Graded porous scaffolds have been verified to be more efficient compared with uniform pore construction in osteogeneses $^{[24,25] \text {. }}$

White Portland cement (WPC) was tested in the last years in different researches. De Deus G et.al., ${ }^{[26]}$ investigated the Cytotoxicity of PC on human endothelial cells. Limited studies have been born out in vivo. Saidon J. et. $\mathrm{Al}^{[27]}$, examined the cell and tissue attitude to PC, while Fabiano S. et. $\mathrm{al},{ }^{[28]}$ evaluate two type of PC in the skull of rats. Therefore, further research should concentrate on the in vivo situation to test the biocompatibility and the possibility of bone healing ability of WPC.
This research examined the histological process of healing and the quantitative measurement of new bone and cell counting of in vivo biocompatibility testing of graft biomaterials. The histology is the most powerful method to evaluate the healing of bone defects, and considered a direct method for testing the biocompatibility ${ }^{[29]}$.

After one week the control defect, histologically showed defect area occupied by fibrous tissue with a clear edge of native bone. Combination of spindle cells, elongated nuclei and small rounded cells with large nuclei were detected in the connective tissue. Osteoclastic activity was evident. MT staining revealed blue-staining fibrous tissues, chronic inflammatory cells were also detected to infiltrate all defect areas, coarse-fibered CT. There were few bone spicules. The amount and size of bone trabecula were increased at the $8^{\text {th }}$ weeks at the center of the bone defect. The rate of bone formation in control defect was delayed, as only few new bone trabeculae were observed at central area and the lateral wall of the bone defect. The surgical cavity was repaired with the reorganization of the bone marrow (MT staining).

These bone trabeculae were limitedly increased in the $8^{\text {th }}$ week. This delaying in bone healing in control side was confirmed by other studies ${ }^{[30,31]}$.

Our histological analysis of $\beta$-TCP (at the end of $1^{\text {st }}$ week) revealed moderate inflamed high cellular CT with collagen fibers and woven bone that is formed at the boundaries of the defect areas in contact with old bone, numerous blood vessels colonizing the granulation tissue, reversal line separating old bone from new bone. At $8^{\text {th }}$ week, new bone trabecular (filling large areas of the bony defect) have mature osteocytes in their lacunae. MT staining in $1^{\text {st }}$ week showed collagen fibers randomly arranged representing an embryonic bone. There was initial bone neoformation. Bone formation became well organized at end of $8^{\text {th }}$ week. 
It is proven that inflammation is a significant element of the host response to biocompatible materials in both acute and chronic periods. Osteoclasts and macrophages are two cell types comprising the major components of the cellular host response that cause the formation of fibrous tissues in place of viable bone tissue ${ }^{[32]}$. Earlier investigations have revealed that $\beta$-TCP granules induce controlled levels of membrane lysis through dissolution of their surfaces. This effect results in high phosphate and low calcium levels, increasing macrophage adhesion behind viable osteoblast adhesion $^{[33]}$. Previous studies have also recognized that purified $\beta$-TCP gives early bone conduction, followed by its resorption and replacement with the newly-formed bone ${ }^{[34]}$.

Although bone tissue in scaffolds provided an uneven distribution and different steps of bone maturity, the structure of the mature part was accustomed with the natural bone in the control group, such as typical lamellar bone blended with woven bone, osteocytes, and Haversian canals.

The histopathological observation of WPC (at the end of $1^{\text {st }}$ week) indicated new bone trabecula surrounded by CT and large blood vessels, active osteoblasts lining the new bone. At end of $8^{\text {th }}$ week, well organized large bone trabeculas were filling large areas of the bone defect. Mature osteocytes in their lacunae. MT staining revealed, the surgical cavity was partially repaired, with incomplete formation of new cortical bone at end of $1^{\text {st }}$ week. In $8^{\text {th }}$ week, thick bone trabeculae are observed.

This finding is in favor of new bone growth in instant contact with the residual space of APC graft material. These results are in agreement with the results obtained by Saidon et $\mathrm{al}^{[35]}$ who reported that in more than $50 \%$ of cases, there were new bone construction in direct contact with Portland cement.

All result of this study showed a pattern of bone formation in WPC similar to the result of other studies testing many grafts ${ }^{[36,37]}$. This pattern of bone formation which start from the wall of the bone defect toward the center, suggests that the WPC material is biocompatible and osteoconductive. In osteoconduction the material promotes an alkaline $\mathrm{pH}$ and releasing of calcium and phosphate elements that stimulate the calcification process, with absence of foreign body reaction and account for the basic mechanisms of physic mchemical healing of hard tissue $^{[38]}$. At present several researches establish that WPC is similar to some commercially available graft material in its basic composition, physical, chemical characteristics, and in biocompatibility ${ }^{[39]}$.

Histomorphometric analysis used MT staining to verify the light microscopic findings. All the experimental phases analyzed in this study showed new bone formation, There were a statistically significant differences between the experimental and the control sides in the amount of new bone formation. At the 8th week of WPC, the highest mean value of quantitative measurement of newly formed bone was reported in the experimental group with the lowest value on the control sides at the 1st week. Shayegan et $\mathrm{al},{ }^{40}$ had the similar result of pulpal tissue repair with hard tissue formation when they used white MTA, WPC and Beta tricalcium phosphate on pulpotomized primary teeth of pigs.

The histopathologic evaluation of the regenerates confirmed comparative results in case of applying both biomaterials $\beta$-TCP \& WPC. Thus it is reasonable to assume that under the present study parameters, the healing of defects is largely driven by the release of porous materials which is able to stimulate osteoblast bone-forming behavior. Attention of living organism is such a complex system that a graded porous proposal is far from biomimicking, more investigations on scaffold construction about scaffold degradation, blood supply improvement, and growth factor release, should be considered. 


\section{CONCLUSIONS}

- With the limitations of this study, it can be concluded that the $\beta$-TCP is a novel biomimetic composite with osteoconductive properties. In this study, we showed that $\beta$-TCP is a viable bone substitute material in the horizontal dimension, both structurally and functionally.

- It seems that the positive histopathological results of this study are promising for the use of WPC as a bone graft substitute.

- More comprehensive studies are necessary before warranting unlimited clinical use.

\section{REFERENCES}

1- Saffar J-L, Lasfargues J-J, Cherruau M. Alveolar bone and the alveolar bone process: the socket that is never stable. Periodontol 2000 1997:13 : 76-90.

2- Schroeder HE. Biological problems of regenerative cementogenesis: synthesis and attachment of collagenous matrices on growing and established root surfaces. Int Rev Cytol 1992:142: 1-59

3- Douglass GL. Alveolar ridge preservation at tooth extraction. J Calif Dent Assoc 2005;33:223-31. Back to cited text no. 1

4- Klokkevold PR, Jovanovic SA. Advanced implant surgery and bone grafting techniques. In: Newman MG, Takei H, Carranza FA, editors. Carranza's Clinical Periodontology. 9th ed. Philadelphia: W.B. Saunders Co.; 2002. p. 907. Back to cited text no. 2

5- Albrektsson T, Johansson C. Osteoinduction, osteoconduction and osseointegration. Eur Spine J 2001;10 Suppl 2:S96-101.

6- Meyer, U., Wiesmann, H.P., Berr, K., Kubler, N.R., andHandschel, J. Cell-based bone reconstruction therapiesprinciples of clinical approaches. Int J Oral Maxillofac Implants 21, 899, 2006.

7- Melvin JS, Veillette C. Orthopaedia - Bone Grafts and Bone Graft Substitutes. In: Orthopaedia - Collaborative Orthopaedic Knowledgebase. Availbale from: http://www. orthopaedicsone.com/display/Main/Bone+grafts+and+bo ne+graft+substitutes. [Last accessed on 2014 Jun 12[

8- Borden M, Attawia M, Khan Y, Laurencin CT.
Tissueengineered microsphere-based matrices for bone repair: Design and evaluation. Biomaterials 2002;23:5519. Back to cited text no. 5

9- Khan SN, Tomin E, Lane JM. Clinical applications of bone graft substitutes. Orthop Clin North Am 2000;31:389-98.

10- Nyan M., Miyahara T., Noritake K., Hao J., Rodriguez R., Kasugai S. Feasibility of alpha tricalcium phosphate for vertical bone augmentation. Journal of Investigative and Clinical Dentistry 2012; 3, 1-8

11- Kihara, H., Shiota, M., Yamashita, Y. \& Kasugai, S. Biodegradation process of $\alpha$-TCP particles and new bone formation in a rabbit cranial defect model. Journal of Biomedical Materials Research Part B: Applied Biomaterials 2006; 79B: 284-291.

12- Rojbani H., Nyan M., Ohya K., Kasugai S. Evaluation of the osteoconductivity of $\alpha$-tricalcium phosphate, $\beta$-tricalcium phosphate, and hydroxyapatite combined with or without simvastatin in rat calvarial defect. J Biomed Mater Res A. 2011; 16. doi: 10.1002/jbm.a.33117.

13- Parirokh M, Torabinejad M. Mineral trioxide aggregate: a comprehensive literature review--Part III: Clinical applications, drawbacks, and mechanism of action. J Endod 2010;36:400-13.

14- Gonçalves JL, Viapiana R, Miranda CE, Borges AH, Cruz Filho AM. Evaluation of physico-chemical properties of Port-land cements and MTA. Braz Oral Res 2010; 24:277-83.

15- Abdullah D, Ford TR, Papaioannou S, Nicholson J, McDonald F. An evaluation of accelerated Portland cement as a restorative material. Biomaterials 2002; 23: 4001-10.

16- Bidar M, Naghavi N, Mohtasham N, Sheik-Nezami M, Fallahrastegar A, Afkhami F, Mashhadi NA, Nargesi I. Mineral trioxide aggregate and portland cement for direct pulp capping in dog: a histopathological evaluation. J Dent Res, Dent Clin, Dent Prosp. 2014:8:134-140.

17- Ravi, K. S., Amit Vanka, and N. D. Shashikiran. "Portland cement: A Building of Evidence for Clinical Use.” International Journal of Dental Clinics 3.1(2011).

18- Marei, H, Mahmood, K and Almas K. Critical Size Defects for Bone Regeneration Experiments in the Dog Mandible: A Systematic Review Implant Dentistry /Volume 27, No. 12017.

19- Callis GM: Bone, Ch: 18 in Bancroft J D and Gamble M (eds), Theory and practice of histological techniques. 6th 
Ed, Churchill Livingstone, 2008:333- 364.

20- Anderson JM. In vivo biocompatibility of implantable delivery systems and biomaterials. Euro j pharmaceu \& biopharmac. 1994:40:1-8.

21- Miloro, M., Haralson, D. J., \&Desa, V. Bone Healing in a Critical-Size Defect Using Platelet-Rich Plasma. indigo. lib.uic.edu. 2010.

22- Lim HP, Mercado-Pagan AE, Yun KD, et al. The effect of rhBMP-2 and PRP delivery by biodegradable betatricalcium phosphate scaffolds on new bone formation in a non-through rabbit cranial defect model. J Mater Sci Mater Med 2013;24:1895-1903.

23- Sanz-Herrera JA, Garcia-Aznar JM, Doblare M. On scaffold designing for bone regeneration: a computational multiscale approach. Acta Biomater 2009; 5:219-229.

24- Kuboki Y, Jin Q, Takita H. Geometry of carriers controlling phenotypic expression in BMP-induced osteogenesis and chondrogenesis. J Bone Joint Surg 2001;83:11.

25- Lan Levengood SK, Polak SJ, Poellmann MJ, et al.,The effect of BMP-2 on micro- and macroscale osteointegration of biphasic calcium phosphate scaffolds with multiscale porosity. Acta Biomater 2010;6:9.

26- De Deus G, Ximenes R, Gurgel-filho E, Plotkowski M, CoutinhoFilho T: Cytotoxicity of MTA and Portland cement on human ECV304 endothelial cells. Int Endod J. 2005: 38:604-609.

27- Saidon J, He J, Zhu Q, Safavi K, Spångberg LS: Cell and tissue reactions to mineral trioxide aggregate and Portland cement. Oral Surg Oral Med Oral Pathol Oral Radiol Endod. 2003:95: 483-489.

28- Fabiano S, Jose Carlos C, Reinaldo D. Macroscopic and microscopic evaluation of Portland Cement Joint - CP I and the Portland Cement White not structural - CPB included in the skull of rats, Brazil, university of saopaulo: Faculdade de Odontologia (FO). 2009(Master theses).

29- Ross MH, Romrell LJ, Kaye GI. Histology - a text and atlas. 3rd ed. Baltimore, MD: Williams \& Wilkins. 1995.

30- Saad KA, Abu-Shahba AG, El-Drieny EA, Khedr MS. Evaluation of the role of autogenous bone-marrow-derived mesenchymal stem cell transplantation for the repair of mandibular bone defects in rabbits. J Cranio-Maxillofac Surg. 2015:43:1151-1160.
31- Cheng G, Li Z, Wan Q, Lv K, Li D, Xing X, Li Z. A novel animal model treated with tooth extraction to repair the full-thickness defects in the mandible of rabbits. J Surg Res. 2015:194:706-716.

32- Lassus, J.; Salo, J.; Jiranek, W.A.; Santavirta, S.; Nevalainen, J.; Matucci-Cerinic, M.; Horák, P.; Konttinen, Y. Macrophage activation results in bone resorption. Clin. Orthop. Relat. Res. 1998, 352, 7-15.

33- John, A.; Varma, H.; Kumari, T. Surface reactivity of calcium phosphate based ceramics in a cell culture system. J. Biomater. Appl. 2003, 18, 63-78.

34- Kondo, N.; Ogose, A.; Tokunaga, K.; Ito, T.; Arai, K.; Kudo, N.; Inoue, H.; Irie, H.; Endo, N. Bone formation and resorption of highly purified $\beta$-tricalcium phosphate in the rat femoral condyle. Biomaterials 2005, 26, 5600-5608.

35- Saidon J, He J, Zhu Q, Safavi K, Spangberg LSW. Cell and tissue reactions to mineral trioxide aggregate and Portland Cement. Oral Surg Oral Med Oral Pathol Oral Radiol Endod 2003; 95:483-9.

36- Gutierres M, Hussain NS, Lopes MA, Afonso A, Cabral AT, Almeida L, Santos JD. Histological and scanning electron microscopy analyses of bone/implant interface using the novel Bonelike ${ }^{\circledR}$ synthetic bone graft. J Orthopaed Res. 2006:24:953-958.

37- Lobato JV, Sooraj Hussain N, Botelho CM, Rodrigues JM, Luis AL, Maurício AC, Lopes MA, Santos JD. Assessment of the potential of Bonelike ${ }^{\circledR}$ graft for bone regeneration by using an animal model. InKey Eng Mater. 2005:284:877-880.

38- Asgary S, Eghbal MJ, Parirokh M, Ghoddusi J, Kheirieh $\mathrm{S}$, Brink F. Comparison of mineral trioxide aggregate's composition with Portland cements and a new endodontic cement. J Endodon. 2009:35:243-250.

39- Chakraborty A. Will portland cement be a cheaper alternative to mineral trioxide aggregate in clinical use?: A comprehensive review of literature. Int J Contemp Dent Med Rev. 2015.

40- Shayegan A, Petein M, Abbeele AV. Beta-tricalcium phosphate, white mineral trioxide aggregate, white Portland cement, ferric sulfate, and formocresol used as pulpotomy agents in primary pig teeth. Oral Surg Oral Med Oral Pathol Oral Radiol Endod. 2008:105:536-542. 